\title{
Prevalence of Refractive Errors in Patients with Keratoconus among Sample of Iraqi Population
}

\author{
Qasim KF1* and Shahad A $^{2}$ \\ 1Department of Ophthalmology, College of Medicine, University of Babylon, Iraq \\ 2Ibn Al Haitham Teaching Eye Hospital, Iraq \\ *Corresponding author: Qasim K Farhood, Department of Ophthalmology, College \\ of Medicine, University of Babylon, Babylon, 52001, Iraq, Tel: +964 780117 9098; E- \\ mail: qasim_1964@ymail.com
}

\section{Research Article}

Volume 2 Issue 4

Received Date: November 18, 2017

Published Date: December 20, 2017

\section{Abstract}

Background: Kerato-conus is a progressive disease of the cornea with deformed keratometry readings, characterize by progressive thinning of corneal apex and corneal ectasia. Keratoconus can affect each layer of the cornea. Keratoconus present in patients with teenage groups and early twenties with complaints of deterioration of vision and frequent change of glasses due to alteration in refractive state of them who develops different types of astigmatism, commonly myopic one.

Aim of Study: The prevalence of refractive errors in patients with keratoconus to explain their clinical characteristics.

Patients \& Methods: This is a retrospective cross sectional research study, in which the clinical data in recorded files were reviewed, (343) eyes of (180) patients with keratoconus, among them (110) were females and (70) were males consulting Al- Najaf refractive surgery center and Al-Hakeem general hospital for correction of their refractive errors during the period between May, 2016 through February, 2017.

Results: The commonest refractive error that present in all grades and age groups of the disease is compound myopic astigmatism (69.7\%) followed by simple myopic astigmatism (25.4\%), mixed astigmatism (3.2\%) then the simple myopia (1.7\%).

Conclusion: The prevalence of keratoconus was higher among patients between (10 to 30) years old. Females were the dominant gender but no significant difference detected in grades of keratoconus and refractive error between genders.

Keywords: Prevalence; Refractive Errors; keratoconus; Iraq; Epithelium

\section{Introduction}

\section{Ametropia}

Refers to the absence of emmetropia. In axial ametropia, the axial length of the eyeball is either unusually longer (myopia) or shorter (hyperopia) than the normal [1].

Astigmatism ( $\mathrm{a}=$ without, stigmas= point) is a refractive state of the eyeball in which rays of light reflected from an object do not focus in a single point because of the 


\section{Open Access Journal of Ophthalmology}

changes in the curvature of the cornea or lens at different meridians [1].

The Pre-Corneal Tear Film: It is composed of "outer lipid" layer, which is produced by the meibomian glands (0.1 $\mu \mathrm{m}$ thickness); "intermediate aqueous" layer, which is produced by the lacrimal glands ( $7 \mu \mathrm{m}$ thickness) and "inner mucous" layer produced by goblet cells of the conjunctiva (0.3 $\mu$ m thickness) [2].

Cornea: It is a transparent avascular structure; its horizontal diameter about $11-12 \mathrm{~mm}$ and its vertical one $10-11 \mathrm{~mm}$. The index of refraction is 1.376 [3]. The cornea is the principal refractive structure of the eyeball and along with sclera it forms the outermost coat of the eye [4].

Epithelium: it is a stratified squamous type and forms $5 \%-10 \%$ of thickness of the cornea. The corneal transparency depends partly on the tight junction of epithelial cells to produce a layer with uniform refractive index and minimum scattering of light [3].

Bowman's Layer: It is acellular outer layer of the stroma and is made of collagen fibers [5].

Stroma: It forms $90 \%$ of thickness of the cornea. It is consist of regularly orientated layers of collagen fiber and keratocytes [5].

Dua's layer: It is the fourth layer of the cornea; Its thickness is $15 \mu \mathrm{m}$ [6].

Descemet's Membrane: It is a discrete sheet consisting of a fine lattice like arrangement of collagen fibrils [5].

The Endothelium: It is inner layer consist of a single layer of polygonal cells. Its function is to maintains corneal deturgescence by pumping the excess fluid out of the stroma [5].

Keratoconus: It is a Greek word (kerato: Cornea; konos: Cone), means conical -shape protrusion of the cornea .It is a progressive disease with progressive distortion of keratometric findings. It is bilateral in $96 \%$ of cases, asymmetry in some cases are also possible [6]. It appears in one eye, and through further progression in the other eye as well within 6 years after the diagnosis [7-10].

Positive family history was reported in $6-8 \%$ of cases. The combination of genetic and environmental factors as frequent rubbing of eyes and inflammation, play a role in the onset and progression of keratoconus $[11,12]$.

Keratoconus can involve all layers of the cornea. The epithelial cells layer may be enlarged and become elongated [13]. Early degeneration of basal epithelial cells leads to disruption of the basement membrane, which results in growth of epithelial cells posterior to the Bowman's layer forming breaks in it [14].

Scarring of the Bowman's layer and the anterior stroma are common. There is a normal-size collagen fibers but low numbers of collagen lamellae in the stroma leading to stromal thinning. Endothelial cells changes in number and size may also be manifested. With progression of the disease, greater change and damage occurs at the base of the cone than at the apex of endothelial cells [15].

Patient with keratoconus presented in the teenage groups and early twenties with complaint of deterioration of vision and going to change glasses continuously due to alteration in refractive state . Irregular myopic astigmatism on retinoscopy usually found, a scissoring like reflex, "oil-droplet" reflex (Charleux sign) are highly suggestive of keratoconus. Vogt's striae are fine parallel lines seen in the posterior stroma which disappear on application of pressure on the globe $[16,17]$.

Fleischer's ring is deposition of hemosiderin around the cone base. In advanced keratoconus, there is a Vshaped distortion of the lower lid in down gaze movement due to protuberant conical cornea (Munson's sign). Acute hydrops in keratoconus caused by sudden breaks in Descemet's membrane leading to corneal clouding and corneal edema results in sudden deterioration of vision $[17,18]$.

Investigations: Corneal topography is standard pre operative test of refractive surgical candidates since the early 1990's [19]. The mainstay for early detection, diagnosis and tracking of ectasia remains videokeratography, specifically the corneal topographic mapping of axial dioptric power with the color-coded contour map [20].

Utilizing Placido-based maps provides the most sensitive and reproducible method for the detection of early ectasia. The amount of information displayed in these maps is determined in part by the topographic scale $[21,22]$.

Ectasia from keratoconus and ectasia following refractive surgery can be remarkably similar, keratoconus 


\section{Open Access Journal of Ophthalmology}

often associated with an inferior localized steepening although the cone can be present centrally or even superiorly [23].

Rabinowitz and Rasheed, recognized that keratoconus can also present as a central symmetric, but lopsided or 'lazy eight' bow tie characterized by the skewed radial axes in the corneal topography. Final characteristic of keratoconus topography is that its progression is usually uneven between the two eyes of a patient and a small number of patients will appear to have unilateral keratoconus [24,25].

Also there are scanning slit-based instruments that measure the position of the two corneal surfaces to yield pachymetry maps which are an important adjunct to corneal topography in the pre operative investigation of patients for photo refractive surgery as well as differentiating keratoconus from pellucid marginal degeneration by the pattern of thinning [26]. The Pentacam and the Galilei ${ }^{\mathrm{TM}}$ Dual Scheimpflug Analyzer imaging systems can further aid in the detection and progression of corneal ectasia [27].

The Orbscan also displays the more clinically useful traditional placido disk keratometric topography and full corneal thickness measurements along a large area of cornea. When screening refractive surgery candidates, several 'red flags' or indices have been associated with possible signs of early ectasia [27] which are:

- Pachymetry measurement with a thinnest point less than $(470-500 \mu \mathrm{m})$.

- Minimum peripheral corneal thickness that is not at least (20 microns) greater than the central cornea.

-Posterior float greater than (50 microns) [28].

-High irregularity at the $3 \mathrm{~mm}$ and $5 \mathrm{~mm}$ corneal zones

-Correlation of the highest to thinnest point on the anterior- posterior pachymetry maps [29].

With Pentacam, by orienting the camera lens and lens plane at intersecting angles, the Scheimpflug camera is able to record the corneal surfaces directly. Direct central recording is unavailable with the traditional Placido devices which places the viewing lens in the center of the Placido mires. Similar to the Orbscan, Pentacam slit images are gathered that image both surfaces of the cornea as well as the surface of the crystalline lens. Anterior elevation of the cornea more than +15 microns is indicative of keratoconus [30].

\section{Aim of Study}

To determine the prevalence of refractive states among Middle Euphrates patients with keratoconus and to describe their clinical criteria.

\section{Patients and Methods}

It is a retrospective study, in which the clinical data in recorded files were reviewed of (343) eyes of (180) patients with keratoconus, among them (110) were females and (70) were males who were consulting AlNajaf refractive surgery center and Al-Hakeem general hospital for correction of their refractive errors during the period between May, 2016 through February, 2017.

The sample collected according to the standard equation of cross section studies:

$\mathrm{N}=\mathrm{Z}^{2} \times \mathrm{PQ}$

$\mathrm{D}^{2}$

$\mathrm{Z}=1.96, \mathrm{P}=$ prevalence according to previous studies, $\mathrm{Q}=$ $1-\mathrm{p}, \mathrm{D}=$ (error) 0.05 .

\section{Inclusion Criteria}

All patients who had complete and filled data files regardless their age and sex were included. Diagnosis of keratoconus were based on slit-lamp examination as mentioned in clinical charts of the patients as Vogt's striae, conical protrusion of the apical cornea, Fleischer ring, corneal topographic measurements using Pentacam Oculyzer topography.

\section{Exclusion Criteria}

Files of patients with incomplete data including unavailability of topographic measures, those without a data of keratometry and or refraction, those with history of ocular injuries or previous corneal refractive surgeries were excluded.

Data were collected by using a data collection sheets (computerized excel Microsoft 2010) including age, sex, refractive errors and severity of keratoconus by the highest axis of corneal power on keratometry classified into mild ( $<48 \mathrm{D})$, moderate (48-54 D) and severe ( $>54$ D) [31].

\section{Ethical Issue}

The Local Research Committee in Al-Najaf Refractive Surgery Centre and the Scientific Council of 


\section{Open Access Journal of Ophthalmology}

Ophthalmology of Iraqi Board for Medical Specializations approved the protocols for the collecting and use of data in the present study.

\section{Statistical Analysis}

Analysis of Data of the 180 keratoconus patients with 343 eyes was done by using the statistical package for social sciences (SPSS) version 24. Chi square and Fisher's exact test had been used to assess the significance of differences in frequencies across different categories. $\mathrm{P}$ value of $\leq 0.05$ considered significant.

\section{Results}

One hundred eighty patients enrolled in this study with 343 eyes, the mean age of studied group was $24.9 \pm 7.9$ years, the majority of patients (78.3\%) aged 30 years or less, males represented $38.9 \%$, while Females $61.1 \%$ of the studied group.

\begin{tabular}{|c|c|c|c|}
\hline Variable & Age groups & Number of patients & \% \\
\hline \multirow{4}{*}{ Age (year) } & $20-$ Oct & 74 & 41.1 \\
\cline { 2 - 4 } & $21-30$ & 67 & 37.2 \\
\cline { 2 - 4 } & $31-40$ & 30 & 16.7 \\
\cline { 2 - 4 } & $>40$ & 9 & 5 \\
\cline { 2 - 4 } & Total & 180 & - \\
\cline { 2 - 4 } & Mean $\pm S D$ & $24.9 \pm 7.9$ & 38.9 \\
\hline \multirow{3}{*}{ Gender } & Male & 70 & 100 \\
\cline { 2 - 4 } & Female & 110 & 100 \\
\cline { 2 - 4 } & Total & 180 & \\
\hline
\end{tabular}

Table 1: Age and gender distribution of the 180 keratoconus patients

As shown in Table 2 Mild keratoconus was reported in 106 eyes (30.9\%), Moderate keratoconus in 110 eyes $(32.1 \%)$ and severe keratoconus in 127 eyes (37.0\%).
However, the distribution of grades according to gender revealed no statistically significant differences between males and females ( $P$ value= 0.087).

\begin{tabular}{|c|c|c|c|c|c|c|c|}
\hline \multirow{2}{*}{ Grade } & \multicolumn{2}{|c|}{ Male } & \multicolumn{2}{c|}{ Female } & \multicolumn{2}{c|}{ Total } & \multirow{2}{*}{ P } \\
\cline { 2 - 7 } & No. & $\mathbf{\%}$ & No. & $\mathbf{\%}$ & No. & $\mathbf{\%}$ & \multirow{2}{*}{ P value } \\
Mild & $\mathbf{4 0}$ & 11.7 & $\mathbf{6 6}$ & 19.2 & $\mathbf{1 0 6}$ & 30.9 & $\mathbf{0 . 0 8 7}$ \\
\hline Moderate & $\mathbf{4 7}$ & 13.7 & $\mathbf{6 3}$ & 18.4 & $\mathbf{1 1 0}$ & 32.1 & \\
\hline Severe & $\mathbf{3 7}$ & 10.8 & $\mathbf{9 0}$ & 26.2 & $\mathbf{1 2 7}$ & 37 & \\
\hline Total & $\mathbf{1 2 4}$ & 36.2 & $\mathbf{2 1 9}$ & 63.8 & $\mathbf{3 4 3}$ & 100 & \\
\hline
\end{tabular}

Table 2: Distribution of patients according to gender and grade of keratoconus ( $\mathrm{N}=343$ eyes).

$*$ Significant $\mathrm{P}$ value $\leq 0.05$.

As shown in table 3. Our results showed no statistically significance according to prevalence of refractive errors in keratoconic eyes with gender ( $\mathrm{P}$ value $\geq 0.05$ ).

\begin{tabular}{|c|c|c|c|c|c|c|c|}
\hline \multirow{2}{*}{ Refractive error } & \multicolumn{2}{|c|}{ Male } & \multicolumn{2}{|c|}{ Female } & \multicolumn{2}{c|}{ Total } & \multirow{2}{*}{ P } \\
\cline { 2 - 7 } & No. & $\mathbf{0}$ & No. & $\mathbf{\%}$ & No. & \% & 0.49 \\
\hline CMA With the rule & $\mathbf{7 4}$ & 21.6 & $\mathbf{1 2 1}$ & 35.3 & $\mathbf{1 9 5}$ & 56.9 & 0.9 \\
\hline CMA Oblique & $\mathbf{1 7}$ & 5 & $\mathbf{2 7}$ & 7.9 & $\mathbf{4 4}$ & 12.8 & 0.84 \\
\hline SMA with the rule & $\mathbf{2 4}$ & 7 & $\mathbf{5 8}$ & 16.9 & $\mathbf{8 2}$ & 23.9 & 0.19 \\
\hline SMA Oblique & $\mathbf{2}$ & 0.6 & $\mathbf{3}$ & 0.9 & $\mathbf{5}$ & 1.5 & 0.98 \\
\hline M & $\mathbf{2}$ & 0.6 & $\mathbf{4}$ & 1.2 & $\mathbf{6}$ & 1.7 & 0.88 \\
\hline MA Against the rule & $\mathbf{2}$ & 0.6 & $\mathbf{2}$ & 0.6 & $\mathbf{4}$ & 1.2 & 0.91 \\
\hline MA Oblique & $\mathbf{3}$ & 0.9 & $\mathbf{4}$ & 1.2 & $\mathbf{7}$ & 2 & 0.98 \\
\hline Total & $\mathbf{1 2 4}$ & 36.2 & $\mathbf{2 1 9}$ & 63.8 & $\mathbf{3 4 3}$ & 100 & \\
\hline
\end{tabular}

Table 3: Prevalence of refractive errors in keratoconus eyes according to gender. 


\section{Open Access Journal of Ophthalmology}

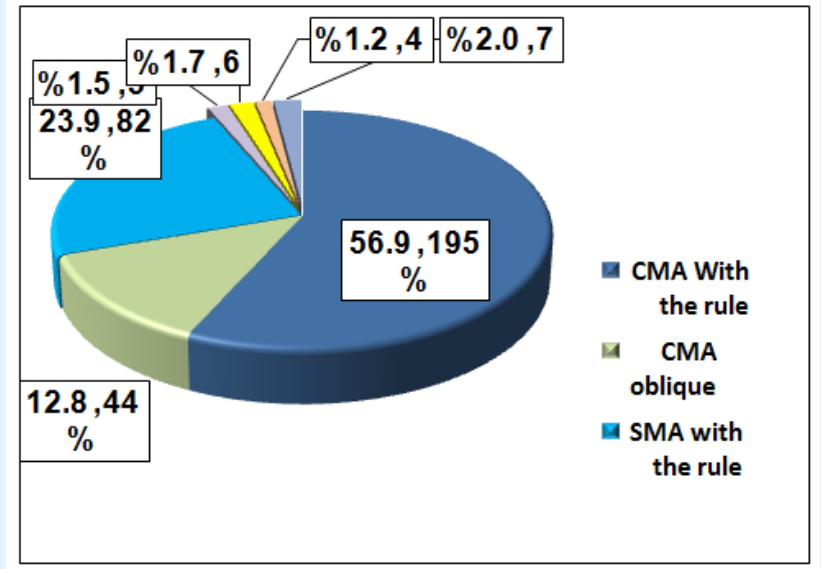

Figure 1: Classification of Refractive errors among 343 eyes of patients with keratoconus.

CMA: compound myopic astigmatism, SMA: simple myopic astigmatism, MA: mixed astigmatism, M: myopia.

Table 4 shows no statistically significant differences had been reported in all refractive errors across the age groups, in all comparisons, (P. value $>0.05$ ).

\begin{tabular}{|c|c|c|c|c|c|c|c|c|c|c|c|}
\hline \multirow{3}{*}{ Refractive error } & \multicolumn{8}{|c|}{ Age (year) } & \multirow{2}{*}{\multicolumn{2}{|c|}{ Total }} & \multirow{3}{*}{$\mathbf{P}$} \\
\hline & \multicolumn{2}{|c|}{ 20-0ct } & \multicolumn{2}{|c|}{$21-30$} & \multicolumn{2}{|c|}{$31-40$} & \multicolumn{2}{|c|}{$>40$} & & & \\
\hline & No. & $\%$ & No. & $\%$ & No. & $\%$ & No. & $\%$ & No. & $\%$ & \\
\hline CMA With the rule & 71 & 20.7 & 82 & 23.9 & 32 & 9.3 & 10 & 2.9 & 195 & 56.9 & 0.17 \\
\hline CMA Oblique & 18 & 5.2 & 13 & 3.8 & 10 & 2.9 & 3 & 0.9 & 44 & 12.8 & 0.46 \\
\hline SMA With the rule & 42 & 12.2 & 29 & 8.5 & 9 & 2.6 & 2 & 0.6 & 82 & 23.9 & 0.34 \\
\hline SMA Oblique & 3 & 0.9 & $\mathbf{0}$ & 0 & 2 & 0.6 & $\mathbf{0}$ & 0 & 5 & 1.5 & 0.17 \\
\hline $\mathrm{M}$ & 4 & 1.2 & 1 & 0.3 & $\mathbf{0}$ & 0 & 1 & 0.3 & 6 & 1.7 & 0.12 \\
\hline MA against the rule & $\mathbf{0}$ & 0 & 2 & 0.6 & 2 & 0.6 & $\mathbf{0}$ & 0 & 4 & 1.2 & 0.28 \\
\hline MA Oblique & 3 & 0.9 & 2 & 0.6 & 2 & 0.6 & $\mathbf{0}$ & 0 & 7 & 2 & 0.68 \\
\hline Total & 141 & 41.1 & 129 & 37.6 & 57 & 16.6 & 16 & 4.7 & 343 & 100 & \\
\hline
\end{tabular}

Table 4: Distribution of total eyes according to Refractive errors and Age

As it shown in table 5, it had been significantly found that compound myopic astigmatism with the rule was more likely to be associated with severe keratoconus $(21.9 \%)$ in Moderate grade $(21.6 \%)$ and in mild grade
$(13.4 \%)$ ( $\mathrm{P}$ value $=0.002)$, other refractive errors show no significant differences in their frequencies, across the grade of keratoconus (P. value $>0.05$ ).

\begin{tabular}{|c|c|c|c|c|c|c|c|c|c|}
\hline \multirow{3}{*}{ Refractive error } & \multicolumn{6}{|c|}{ Keratoconus Grade } & \multirow{2}{*}{\multicolumn{2}{|c|}{ Total }} & \multirow{3}{*}{$\mathbf{P}$} \\
\hline & \multicolumn{2}{|c|}{ Mild } & \multicolumn{2}{|c|}{ Moderate } & \multicolumn{2}{|c|}{ Severe } & & & \\
\hline & No. & $\%$ & No. & $\%$ & No. & $\%$ & No. & $\%$ & \\
\hline CMA With the rule & 46 & 13.4 & 74 & 21.6 & 75 & 21.9 & 195 & 56.9 & $0.002 *$ \\
\hline CMA Oblique & 11 & 3.2 & 15 & 4.4 & 18 & 5.2 & 44 & 12.8 & 0.65 \\
\hline SMA With the rule & 33 & 9.6 & 18 & 5.2 & 31 & 9 & 82 & 23.9 & 0.36 \\
\hline SMA Oblique & 5 & 1.5 & $\mathbf{0}$ & 0 & $\mathbf{0}$ & 0 & 5 & 1.5 & $* *$ \\
\hline M & 2 & 0.6 & 1 & 0.3 & 3 & 0.9 & 6 & 1.7 & 0.74 \\
\hline MA Against the rule & 4 & 1.2 & $\mathbf{0}$ & 0 & $\mathbf{0}$ & 0 & 4 & 1.2 & ** \\
\hline MA Oblique & 5 & 1.5 & 2 & 0.6 & $\mathbf{0}$ & 0 & 7 & 2 & 0.69 \\
\hline Total & 106 & 30.9 & 110 & 32.1 & 127 & 37 & 343 & 100 & \\
\hline
\end{tabular}

Table 5: Classification of refractive errors according to grades of keratoconus

*Significant $\mathrm{P}$ value $\leq 0.05$.

**cannot be calculated. 


\section{Open Access Journal of Ophthalmology}

\section{Discussion}

Keratoconus is a degenerative disease that results in corneal thinning and ectasia leading to irregular light reflexes on retinoscopy [32]. The patient eyes develop different variants of astigmatism especially myopic astigmatism. As the corneal curvature increased, the degree of astigmatism also increases causing a reduction in visual acuity of patient's eyes [33]. There are few relevant studies on other refractive errors that can be found in keratoconus, which we try, to asses in our study.

Our study showed that the mean age of patients with keratoconus was $(24.9 \pm 7.9)$, which is comparable with the results of other studies as those done in Asia by Saini $\mathrm{G}$ et al. [33], they found the mean age of patients was

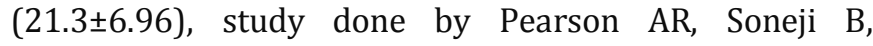
Sarvananthan N, et al. [34] on white patients, showed that the mean age was (26.5 \pm 8.5 years) and a study done in Mexican by Aníbal Cruz-Becerril et al. [35] reported that the mean age was (28.14 \pm 10.30$)$.

The results of our study revealed that the female was predominant in which the prevalence rate $(61.1 \%)$ and (38.9\%) for females and males respectively. This finding come in line with a results of several previous studies, one done by Huseyin Serdarogullari, Mehmet Tetikoglu, et al. in which they found (60.9\%) female and (39.1\%) male subjects [36]. Other study by Jorge E. Valdez-García et al. found prevalence rates was (66.6\%) female and $(33.3 \%)$ male [37]. While others found that a greater prevalence in males as shown in study done by Owens $\mathrm{H}$ and Gamble $\mathrm{G}$, et al. in which (59\%) was male [38], And also the result of Mustafa Abdu, et al. concluded that keratoconus is more common in males (55.8\%) than females (44.2\%) [39]. Others found no significant differences between genders as in the study of Kennedy RH, Bourne WM, Dyer JA, et al. and study done by Li X, Rabinowitz YS, et al. mentioned $[40,41]$.

The sex differences can be caused by biological diversity between male and female, such as hormonal changes as an effect of the menstrual cycle, pregnancy and menopause, which may lead to anatomical and physiological differences between male and female [42].

About the severity of keratoconus we found that $(37.0 \%)$ are severe, (32.1\%) moderate and (30.9\%) of cases were mild. Similar results were observed in other researches as one done in Kenya by Zahra Aly Rashid, et al. mentioned that severe keratoconus in (71\%) followed by moderate in (22.9\%) and mild keratoconus in $(6.2 \%)$
[43]. Tarannum Fatima, et al. found that severe keratoconus in (49\%) of cases and (36.7\%) were moderate [44], while in other studies they found that moderate keratoconus was more frequent like study done in Iran by Naderan M, Shoar S, et al. in which they found that moderate keratoconus was (43.8\%) while the severe keratoconus (41\%) [45]. Bilgin LK, et al. In Turkey found that (53.4\%) of keratoconus was moderate [46], other study in USA by Azadnik K, et al. Reported that (48.7\%) moderate and (46.7\%) was severe [47].

In our study there is no significant difference in grades of keratoconus between genders ( $p$ value $=0.087$ ). This result agrees in line with studies done by Mustafa Abdu, et al. [39] and Bariah Mohd Ali, et al. which also demonstrated no statistically significant difference between genders in grades of keratoconus [48].

In the current study, the majority of cases were compound myopic astigmatism (69.7\%) that is found in all grades and age groups of the disease and significantly found that compound myopic astigmatism with the rule was more likely to be associated with Severe keratoconus $(21.9 \%)$,in moderate grade $(21.6 \%)$ and in mild grade $(13.4 \%)$ where $(\mathrm{P}$ value $=0.002)$, followed by simple myopic astigmatism (25.4\%), mixed astigmatism (3.2\%) which is not present in severe keratoconus and those patient with age $>40$ years, it was more frequent in mild keratoconus probably due to the corneal curvature was close to emmetropia, then the simple myopia (1.7\%). This finding is comparable with Aníbal Cruz-Becerril et al. results which concluded that compound myopic astigmatism was the commonest refractive error among patients with keratoconus, being present in (87.5\%) of eyes, simple myopic astigmatism (5.5\%), mixed astigmatism in $(4.7 \%)$ and myopia was present in $(0.8 \%)$ [35].

\section{Conclusions and Recommendations}

1. The prevalence of keratoconus was higher among patients between 10 to 30 years old.

2. Females were the dominant gender among keratoconus patients but no significant difference was detected in grades of keratoconus and refractive error between genders.

3. Severe keratoconus is more frequent followed by moderate then mild.

4. Compound myopic astigmatism found in majority of cases of keratoconus followed by simple myopic astigmatism, mixed astigmatism, then the simple myopia. 


\section{Open Access Journal of Ophthalmology}

5. We recommend screening program for Keratoconus particularly among young individuals with astigmatism as it affect quality of life and productivity of patients.

6. Simple myopia may be early presentation of keratoconus which should pay attention.

\section{References}

1. American Academy of Ophthalmology (2015) Basic and Clinical Science Course Clinical Optics, Section 3. San Francisco, CA: American Academy of Ophthalmology, PP: 6-39.

2. Kanski JJ, Bowling B (2011) Clinical Ophthalmology. $7^{\text {th }}$ (Edn.), China: Elsevier 6: 120.

3. American Academy of Ophthalmology (2015) Basic and Clinical Science Course. External Disease and Cornea, Section 8. San Francisco, CA: American Academy of Ophthalmology, pp: 6-39.

4. Sharma N, Vajpayee RB (2008) Corneal Ulcer Diagnosis and Management. Jaypee Brothers Medical Publishers, New Delhi-India, pp: 1,3,5,6.

5. Bowling B (2016) Dry Eye, Kanski's Clinical Ophthalmology, A Systematic Approach. 8 $8^{\text {th }}($ edn), China: Elsevier group, pp: 120.

6. Dua HS, Faraj LA, Said DG, Gray T, Lowe J (2013) Human corneal anatomy redefined: a novel preDescemet's layer (Dua's layer). Ophthalmology 120(9): 1778-1785.

7. Tuft SJ, Moodaley LC, Gregory WM, Davison CR, Buckley RJ (1994) Prognostic factors for the progression of keratoconus. Ophthalmology 101(3): 439-447.

8. Holland DR, Maeda N, Hannush SB, Riveroll LH, Green MT, et al. (1997) Unilateral keratoconus: incidence and quantitative topographic analysis. Ophthalmology 104(9): 1409-1413.

9. Assiri AA, Yousuf BI, Quantock AJ, Murphy PJ (2005) Incidence and severity of keratoconus in Asir province, Saudi Arabia. Br J Ophthalmology 89(11): 1403-1406.

10. Tsubota K, Mashima $Y$, Murata H, Sato N, Ogata T (1995) Corneal epithelium in keratoconus. Cornea 14(1): 77-83.
11. Sawaguchi S, Fukuchi T, Abe H, Kaiya T, Sugar J, Yue BY (1998) Three-dimensional scanning electron microscopic study of keratoconus corneas. Arch Ophthalmology 116(1): 62-68.

12. Sturbaum CW, Peiffer RL (1993) Pathology of corneal endothelium in keratoconus. Ophthalmologica 206(4): 192-208.

13. McGhee CN (2009) 2008 Sir Norman McAlister Gregg Lecture: 150 years of practical observations on the conical cornea-what have we learned?. Clin Exp ophthalmol 37(2): 160-176.

14. Rabinowitz YS (1998) Keratoconus. Survey of ophthalmology 42(4): 297-319.

15. Balasubramanian SA, Pye DC, Willcox MD (2012) Levels of lactoferrin, secretory IgA and serum albumin in the tear film of people with keratoconus. Exp Eye Res 96(1): 132-137.

16. Wilson SE, Klyce SD (1991) Advances in the analysis of corneal topography. Surv Ophthalmol 35(4): 269277.

17. Maguire LJ, Singer DE, Klyce SD (1987) Graphic presentation of computer-analyzed keratoscope photographs. Arch Ophthalmol 105(2): 223-230.

18. Wilson SE, Klyce SD, Husseini ZM (1993) Standardized color-coded maps for corneal topography. Ophthalmology 100(11): 1723-1727.

19. Smolek MK, Klyce SD, Hovis JK (2002) The Universal Standard Scale: proposed improvements to the American National Standards Institute (ANSI) scale for corneal topography. Ophthalmology 109(2): 361369.

20. Wilson SE, Lin DT, Klyce SD (1991) Corneal topography of keratoconus. Cornea 10(1): 2-8.

21. Rabinowitz YS, Rasheed K (1999) KISA\% index: a quantitative videokeratography algorithm embodying minimal topographic criteria for diagnosing keratoconus. J Cataract Refractive Surg 25(10): 13271335.

22. Klyce SD, Karon MD, Smolek MK (2005) Screening patients with the corneal navigator. J Refractive surg 21(5): S617-S622. 


\section{Open Access Journal of Ophthalmology}

23. Randleman JB, Trattler WB, Stulting RD (2008) Validation of the Ectasia Risk Score System for preoperative laser in situ keratomileusis screening. Am J ophthalmology 145(5): 813-818.

24. Klein SR, Epstein RJ, Randleman JB, Stulting RD (2006) Corneal ectasia after laser in situ keratomileusis in patients without apparent preoperative risk factors. Cornea 25(4): 388-403.

25. Cho P, Cheung SW (2002) Repeatability of corneal thickness measurements made by a scanning slit topography system. Ophthalm Physiol Opt 22(6): 505-510.

26. Maus M, Krober S, Swartz T, Belin MW, Michaelson M, et al. (2006) In Wang M (Eds): Corneal Topography in the Wavefront Era, Chapter 24, Slack, Inc, Thorofare, NJ, pp: 281-293.

27. Brad Bowling. Kanski's Clinical Ophthalmology a systemic approach, chapter 6th Cornea, $8^{\text {th }}$ (edn), pp: 213-214.

28. Rabinowitz YS, Nesburn AB, McDonnell PJ (1993) Videokeratography of the fellow eye in unilateral keratoconus. Ophthalmology 100(2): 181-186.

29. Patel A, Shah S (2012) Corneal degenerations and keratoconus. Optometry Today 52(21): 49-53.

30. Saini JS, Saroha V, Singh P, Sukhija JS, Jain AK (2004) Keratoconus in Asian eyes at a tertiary eye care facility. Clin Exp Optom 87(2): 97-101.

31. Aníbal Cruz-Becerril, Alejandra Valdivia, Raúl Peralta, Ruth N DomínguezFernández, Marco a Castro-reyes (2015) Prevalence of refractive errors in Mexican patients with keratoconus. Dovepress J Clinical optometery 7: 39-44.

32. Serdarogullari H, Tetikoglu M, Karahan H, Altin F, Elcioglu M (2013) Prevalence of keratoconus and subclinical keratoconus in subjects with astigmatism using pentacam derived parameters. J ophthal Vis Res 8(3): 213-219.

33. Valdez-García JE, Sepúlveda R, Salazar-Martínez JJ, Lozano-Ramírez JF (2014) Prevalence of keratoconus in an adolescent population. Revista Mexicana de Oftalmología 88(3): 95-98.

34. Owens H, Gamble G (2003) A profile of keratoconus in New Zealand. Cornea 22(2): 122-125.
35. Abdu M, Binnawi KH, Elmadina AE, Hassan R (2016) Clinical profile of keratoconus patients in Sudan. Sudanese J Ophthalmol 8(1): 20-25.

36. Kennedy RH, Bourne WM, Dyer JA (1986) A 48-year clinical and epidemiologic study of keratoconus. Am J Ophthalmol 101(3): 267-273.

37. Li X, Rabinowitz YS, Rasheed K, Yang H (2004) Longitudinal study of the normal eyes in unilateral keratoconus patients. Ophthalmology 111(3): 440446.

38. Ertan A, Muftuoglu O (2008) Keratoconus clinical findings according to different age and gender groups. Cornea 27(10): 1109-1113.

39. Rashid ZA, Millodot M, Evans KS (2016) Characteristics of keratoconic patients attending a specialist contact lens clinic in Kenya. Middle East African J Ophthalmology 23(4): 283-287.

40. Fatima T, Acharya MC, Mathur U, Barua P (2010) Demographic profile and visual rehabilitation of patients with keratoconus attending contact lens clinic at a tertiary eye care centre. Cont Lens and Anterior Eye 33(1): 19-22.

41. Naderan M, Shoar S, Rezagholizadeh F, Zolfaghari M, Naderan M (2015) Characteristics and associations of keratoconus patients. Contact Lens and Anterior Eye 38(3): 199-205.

42. Bilgin LK, Yılmaz Ş, Araz B, Yüksel SB, Sezen T (2009) 30 years of contact lens prescribing for keratoconic patients in Turkey. Contact lens and anterior eye 32(1): 16-21.

43. Zadnik K, Barr JT, Edrington TB, Everett DF, Jameson M, McMahon TT, et al. (1998) Baseline findings in the Collaborative Longitudinal Evaluation of Keratoconus (CLEK) Study. Invest ophthalmol Vis Sci 39(13): 2537-2546.

44. Mohd-Ali B, Abdu M, Yaw CY, Mohidin N (2012) Clinical characteristics of keratoconus patients in Malaysia: a review from a cornea specialist centre. J Optom 5(1): 38-42.

45. Pearson AR, Soneji B, Sarvananthan N, SandfordSmith JH (2000) Does ethnic origin influence the incidence or severity of keratoconus?. Eye (Lond) 14(4): 625-628. 